\title{
Age-specific definition of low anti-Mullerian hormone and associated pregnancy outcome in women undergoing IVF treatment
}

Depeng Zhao, Jing Fan, Ping Wang, Xuan Jiang, Jilong Yao and Xuemei Li

\begin{abstract}
Background: The age-specific definition of low anti-müllerian hormone (AMH) is lacking. This study aims to define an age-specific reference for low AMH and to evaluate the associated outcome in women undergoing IVF treatment.

Methods: A retrospective study was performed in women receiving IVF treatment at the Shenzhen maternity and child healthcare hospital between September 2016 and September 2018. We excluded cases without AMH concentration. Polynomial least-squares regression was used to estimate the age-specific reference ranges for $\mathrm{AMH}$ after log-transformed. The age-specific $10^{\text {th }}$ centile was defined as the threshold of low AMH concentration.

Results: A total of 909 patients were analyzed in this study. The age-specific reference ranges for AMH were established using linear regression model and resulted in an age-specific equation for mean: mean of $\mathrm{LnAMH}=$ $(-0.085 \times$ age $)+3.722\left(\mathrm{ng} / \mathrm{ml}\right.$, in unit). Women with $\mathrm{AMH}$ level higher than $10^{\text {th }}$ centile had favorable outcomes in ovarian stimulation compared to those with low AMH level. In patients younger than 35 years, the rates of clinical pregnancy per transfer and ongoing pregnancy per transfer in the subgroup with $\mathrm{AMH}$ level higher than $10^{\text {th }}$ centile were significantly higher than that in the subgroup of low AMH level, 57\% versus $31.3 \% p=0.003$ and $51.9 \%$ versus $21.9 \% p=0.001$, respectively.

Conclusion: Women with AMH lower than age-specific $10^{\text {th }}$ centile had significantly unfavorable outcomes after IVF treatment. The age-specific $10^{\text {th }}$ centile of $\mathrm{AMH}$ concentration may be useful to predict the outcome of IVF treatment.
\end{abstract}

Keywords: Anti-Mullerian hormone, Age, In vitro fertilization, Pregnancy

\section{Background}

The anti-Mullerian hormone $(\mathrm{AMH})$ belongs to the superfamily of transforming growth factor- $\beta$ (TGF- $\beta$ ) and is mainly expressed in granulosa cells of small follicles $\leq 8$ $\mathrm{mm}$ diameter [1]. In ovarian folliculognensis, $\mathrm{AMH}$ inhibits the primordial to primary follicle transition and limits the number of early atrial follicles which will

\footnotetext{
* Correspondence: LXMYZF@126.com

This study was present at the 2019 IFFS Shanghai World Congress. Department of Reproductive Medicine, Shenzhen Maternity and Child Healthcare Hospital, Southern Medical University, Shenzhen, China
}

develop into dominant follicle for ovulation [2]. The serum AMH level thus well corresponds to the number of atrial follicles in ovaries [3]. As a result, AMH is widely applied to test the ovarian reserve in women undergoing IVF treatment and recently to predict pregnancy outcome after assisted conception [4]. Several retrospective studies reported a positive association of AMH level with pregnancy rates after IVF treatment $[5,6]$. These findings were confirmed in a large prospective study and a metaanalysis $[7,8]$. Nevertheless, other studies reported a weak or not significant association between AMH level and pregnancy

(c) The Author(s). 2021 Open Access This article is licensed under a Creative Commons Attribution 4.0 International License, which permits use, sharing, adaptation, distribution and reproduction in any medium or format, as long as you give appropriate credit to the original author(s) and the source, provide a link to the Creative Commons licence, and indicate if changes were made. The images or other third party material in this article are included in the article's Creative Commons licence, unless indicated otherwise in a credit line to the material. If material is not included in the article's Creative Commons licence and your intended use is not permitted by statutory regulation or exceeds the permitted use, you will need to obtain permission directly from the copyright holder. To view a copy of this licence, visit http://creativecommons.org/licenses/by/4.0/. The Creative Commons Public Domain Dedication waiver (http://creativecommons.org/publicdomain/zero/1.0/) applies to the data made available in this article, unless otherwise stated in a credit line to the data. 
outcome [9-11]. Therefore, AMH may be a potential predictor for pregnancy outcome after assisted conceptions, but further investigation is still warranted.

The serum AMH level decreases steadily with advancing age. Most previous studies however used an arbitrary cut-off value from 0.4 to $2.7 \mathrm{ng} / \mathrm{ml}$ based on the method used for assay to differentiate pregnancy outcome [12]. The AMH level varies greatly in women at same age $[13,14]$. A universal threshold of $A M H$ level may result in that the majority of women at advanced age are classified into the low AMH group, subsequently leading to a poor pregnancy outcome after IVF conception. In addition, maternal age after 35 years is strongly related to embryonic aneuploidy, increased miscarriage rate and decreased live birth rate [15]. The age-specific cut-off value of low AMH could be thus useful to investigate the association of AMH with pregnancy outcome in assisted conceptions. The purpose of this study is to establish an age-specific cut-off value for low AMH level and to investigate the association between low AMH level and pregnancy outcome in a large cohort of women undergoing IVF treatment.

\section{Methods}

\section{Study subjects}

All women undergoing IVF treatment at the Department of Reproductive Medicine, Shenzhen Maternity and Child Healthcare Hospital from January 2016 to October 2018 were included in the present study. Women with no AMH measurement were excluded from this study. In analysis of pregnancy outcome, only the first embryo transfer was included. All the oocyte retrieval cycles and subsequent frozen embryo transfer if performed during this study period were analyzed. The data on IVF treatment and pregnancy outcome were retrieved from the electronic medical database. Diminished ovarian reserve was defined as serum AMH $<1 \mathrm{ng} / \mathrm{ml}$ or serum FSH $>$ $15 \mathrm{IU} / \mathrm{l}$ and $\mathrm{AFC}<4$ on day $2-5$ of the menstrual cycle [16]. Diagnosis of polycystic ovary syndrome (PCOS) was based on the modified Rotterdam criteria [17].

\section{Ethics approval and consent to participate}

This study was approved by the Medical Ethics Committee of Shenzhen Maternity and Child Healthcare Hospital (SFYLS2019048). Given the retrospective nature of this study, the informed consent waived by the Medical Ethics Committee of Shenzhen Maternity and Child Healthcare Hospital.

\section{Blood samples and hormone test}

Venous blood samples (about $3 \mathrm{ml}$ ) were drawn between day 2 and 5 of the menstrual period before ovarian stimulation. After collection, blood samples could clot at room temperature for 20 to $30 \mathrm{~min}$. Fresh Serum was then separated by centrifugation $(10 \mathrm{~min}$ at $1500 \mathrm{~g})$ and analyzed within $8 \mathrm{~h}$ after blood collection. Serum FSH concentrations were measured using a standard chemiluminescence immunoassay (Beckman DXI800, Brea, California, USA) following the manufacturer 's instructions. The lower detection concentration was $0.1 \mathrm{mIU} /$ $\mathrm{ml}$. Serum AMH concentrations were measured by a one-step sandwich assay based on the acridinium direct chemiluminescence technology for use on iFlash 3000 immunoanalyzers (YHLO Biotech, Shenzhen, China). The assay limit of detection was $0.03 \mathrm{ng} / \mathrm{ml}$ for AMH provided by the manufacturer [18]. The intra- and interassay coefficients of variation were $<10 \%$ for all parameters.

\section{Controlled ovarian stimulation and embryo scoring}

The controlled ovarian stimulation (COS) protocol for each patient was decided by the infertility physicians. The utility of gonadotropin-releasing hormone ( $\mathrm{GnRH})$ agonist or GnRH antagonist or no pituitary suppression regimen for COS procedures was based on a real-life approach. Follicular growth was monitored by serial ultrasound scans and serum hormone test. Triggering of ovulation was performed when at least one follicle reached a size of $17 \mathrm{~mm}$ or more. In extreme majority of cases, 10,000 IU human chorionic gonadotrophin was administered for triggering. Oocyte retrieval was scheduled $36 \mathrm{~h}$ later. The quality of a day 3 embryo was graded based on the number and symmetry of blastomeres and the amount of fragmentation. The scoring criteria of blastocyst quality included evaluation of the trophectoderm and the inner cell mass or inner cell mass (ICM), the degree of expansion of the blastocyst cavity and the status of the trophectoderm breakings out of the zona pellucida.

\section{Embryo transfer and pregnancy outcome follow-up}

Embryo transfer was scheduled on cleavage-stage day 3 or 5 in all cases. Either natural, programmed or mild stimulation regimens was applied for endometrial preparation in frozen embryo cycles. The number of embryos transferred was based on the guidelines of the Chinese Society of Reproductive Medicine and American Society for Reproductive Medicine [19]. Dydrogesterone (10 mg tid) and P suppository (Cyclogest, $400 \mathrm{mg}$ bid) or $8 \%$ Crinone gel $(90 \mathrm{mg} \mathrm{qd})$ were used for luteal support. Serum $\beta$ human chorionic gonadotrophin $(\beta-h C G)$ test was conducted 14 days after oocyte retrieval. Biochemical pregnancy was defined by a transient positive $\beta$-hCG test without the presence of gestational sac. Clinical pregnancy was diagnosed as the presence of gestational sac and heart beat detected by transvaginal ultrasonography 4 weeks after embryo transfer. Miscarriage was defined as the loss of clinical pregnancy prior to 24 weeks. 
Live birth was defined as the birth of at least one live infant after 24 weeks of gestation. The implantation rate, clinical pregnancy, miscarriage and ongoing pregnancy per embryo transfer were calculated.

\section{Data collection and statistics}

A dedicated SPSS-based database was built for data retrieval and management. The data on patients' demographics, COS, embryo transfer and pregnancy outcomes were recorded. A well-trained research nurse was responsible for the follow-up of pregnancy outcome and maintenance of the database. Chi-square test or Fisher's exact test was applied to analyze the qualitative data. Independent-samples $t$ test or Manne-Whitney $U$ test was adapted to compare continuous variables. Shapiro-Wilk test was used to test the normality of continuous variables. The method to establish age-specific reference range for $\mathrm{AMH}$ was described in our previous report [20]. In details, the $\mathrm{AMH}$ concentrations at a given age had no Gaussian distribution with a mean and standard deviation varying greatly across ages. Therefore, the absolute AMH concentrations were log-transformed to be normal distribution. Subsequently, polynomial least-squares regression was applied to estimate the association between $\log \mathrm{AMH}$ and age in the entire study cohort. The coefficients of determination $\left(R^{2}\right)$ in the linear regression model $\left(R^{2}=0.18\right)$ were greater than that in the quadratic regression model $\left(R^{2}=0.10\right)$. The linear regression equation was thus chosen to build the reference range of $\log \mathrm{AMH}$ across ages. The $10^{\text {th }}$ and $90^{\text {th }}$ centile of the reference age were also calculated. An agespecific low AMH concentration was defined as an
AMH level equal or lower than the $10^{\text {th }}$ centile at each age. Female age after 35 was directly related to increased risk of embryonic aneuploidy and decreased rare of cumulative live birth rates [21]. This study used the age 35 as the cutoff value to clarify the confounding of female age in the association of low $\mathrm{AMH}$ with pregnancy outcome.

\section{Results}

A total of 909 patients with AMH concentration available were included during the study period. In the total cohort, serum AMH concentrations were inversely correlated with age (Spearman $\mathrm{r}=-0.43 ; P<0.001$ ). The Ln-transformation of serum AMH levels were used to build the age-related reference range, yielding the fitted curves for the mean LnAMH and the $10^{\text {th }}$ centile (Fig. 1 and Table 1). Their equations were as follows: mean LnAMH $=(-0.085 \times$ age $)+3.714$ and $10^{\text {th }}$ centile $=(-$ $0.107 \times$ age $)+3.39$, respectively. Accordingly, 62 patients were categorized into the group of low AMH level. The comparison of clinical characteristics between patients with and without low AMH level were summarized in Table 2. The indications for IVF treatment were quite different between two groups. Diminished ovarian reserve was the main cause $(88.7 \%)$ for IVF treatment in patients with low AMH levels.

The data on COS procedures and embryo culture were recapitulated in Table 3. A total of 1281 COS procedures were performed. In these 909 women, 680 women underwent 1 cycle of oocyte retrieval, 152 did 2 cycles of oocyte retrieval, 39 did 3 cycles of oocyte retrieval, 22 did 4 cycles of oocyte retrieval, 8 did 5 cycles of oocyte

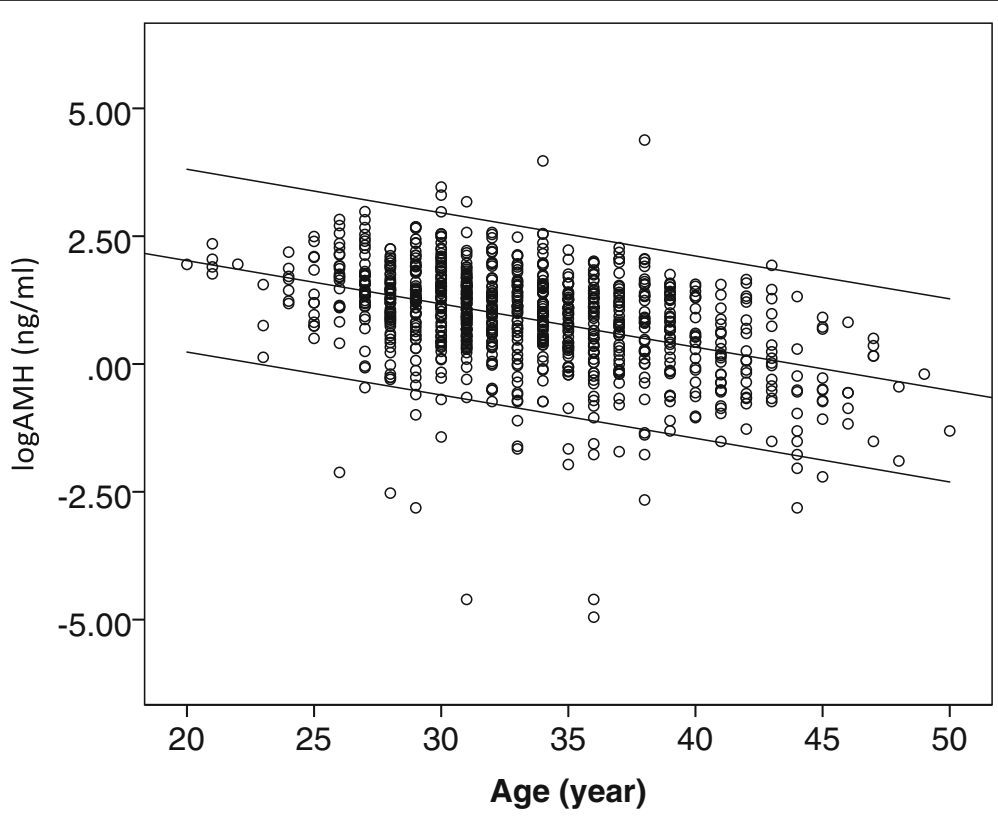

Fig. 1 Scatter plot of AMH across ages and the estimated reference range with curves of $10^{\text {th }}$ and $90^{\text {th }}$ centiles 
Table 1 The estimated cut-off value of various centiles across ages

\begin{tabular}{|c|c|c|c|c|c|}
\hline Age, year & $5^{\text {th }}$ centile & $10^{\text {th }}$ centile & $50^{\text {th }}$ centile & $90^{\text {th }}$ centile & $95^{\text {th }}$ centile \\
\hline 20 & 2.81975 & 3.50425 & 7.54972 & 16.2655 & 20.2139 \\
\hline 21 & 2.51792 & 3.14896 & 6.93721 & 15.2828 & 19.113 \\
\hline 22 & 2.24839 & 2.82969 & 6.3744 & 14.3595 & 18.072 \\
\hline 23 & 2.00772 & 2.5428 & 5.85725 & 13.492 & 17.0877 \\
\hline 24 & 1.79281 & 2.28499 & 5.38205 & 12.6769 & 16.1571 \\
\hline 25 & 1.6009 & 2.05332 & 4.94541 & 11.911 & 15.2771 \\
\hline 26 & 1.42953 & 1.84514 & 4.54419 & 11.1914 & 14.445 \\
\hline 27 & 1.27651 & 1.65806 & 4.17552 & 10.5153 & 13.6583 \\
\hline 28 & 1.13987 & 1.48995 & 3.83677 & 9.88 & 12.9144 \\
\hline 29 & 1.01786 & 1.33889 & 3.52549 & 9.2831 & 12.211 \\
\hline 30 & 0.9089 & 1.20314 & 3.23947 & 8.7223 & 11.546 \\
\hline 31 & 0.81161 & 1.08116 & 2.97665 & 8.1954 & 10.9171 \\
\hline 32 & 0.72473 & 0.97154 & 2.73516 & 7.7002 & 10.3225 \\
\hline 33 & 0.64716 & 0.87304 & 2.51326 & 7.235 & 9.7603 \\
\hline 34 & 0.57788 & 0.78452 & 2.30936 & 6.7979 & 9.2287 \\
\hline 35 & 0.51603 & 0.70498 & 2.122 & 6.3872 & 8.7261 \\
\hline 36 & 0.46079 & 0.63351 & 1.94985 & 6.0014 & 8.2509 \\
\hline 37 & 0.41146 & 0.56928 & 1.79166 & 5.6388 & 7.8015 \\
\hline 38 & 0.36742 & 0.51156 & 1.6463 & 5.2981 & 7.3766 \\
\hline 39 & 0.32809 & 0.45969 & 1.51274 & 4.9781 & 6.9748 \\
\hline 40 & 0.29297 & 0.41308 & 1.39001 & 4.6773 & 6.5949 \\
\hline 41 & 0.26161 & 0.3712 & 1.27724 & 4.3947 & 6.2358 \\
\hline 42 & 0.23361 & 0.33357 & 1.17362 & 4.1292 & 5.8961 \\
\hline 43 & 0.2086 & 0.29975 & 1.0784 & 3.8798 & 5.575 \\
\hline 44 & 0.18627 & 0.26936 & 0.99091 & 3.6454 & 5.2714 \\
\hline 45 & 0.16633 & 0.24205 & 0.91052 & 3.4251 & 4.9843 \\
\hline 46 & 0.14853 & 0.21751 & 0.83665 & 3.2182 & 4.7128 \\
\hline 47 & 0.13263 & 0.19545 & 0.76877 & 3.0238 & 4.4561 \\
\hline 48 & 0.11843 & 0.17564 & 0.7064 & 2.8411 & 4.2134 \\
\hline 49 & 0.10575 & 0.15783 & 0.64909 & 2.6695 & 3.9839 \\
\hline 50 & 0.09443 & 0.14183 & 0.59643 & 2.5082 & 3.767 \\
\hline
\end{tabular}

Data were the age-specific $5^{\text {th }}, 10^{\text {th }}, 50^{\text {th }}, 90^{\text {th }}$ and $95^{\text {th }}$ centile of $\mathrm{AMH}$ values in unit of $\mathrm{ng} / \mathrm{ml}$

retrieval, 5 did 6 cycles of oocyte retrieval, 2 did 7 cycles of oocyte retrieval and 1 did 8 cycles of oocyte retrieval. All the analyzed parameters were significant different between patients with or without low AMH level $(p<$ 0.01 ). The mean number of embryos available per cycle was significantly fewer in patients with low AMH level $(0.8 \pm 1.1)$ compared to patients without low AMH level $(3.4 \pm 2.7), p<0.01$. When further stratified according to age, the outcomes of ovarian stimulation and embryo culture in patients with or without low AMH level remained to be significantly different (Table 4).

Table 5 presents the embryo transfer by AMH percentile according to patient age. A total of 1008 fresh or frozen embryo transfer cycles were performed. In patients younger than 35 years, transfer of D3 embryos was more frequently in patients with low AMH level compared to patients with no low AMH level (96.9 and 78.7\%, respectively, $p<$ 0.01 ). However, this difference was not detected in patients with age $\geq 35$ years.

Univariate regression analysis displayed a significant association of ongoing pregnancy with AMH concentration, oocyte number and female age (OR 1.11, 95\% CI $1.06-1.16$, OR $=1.05,95 \% \mathrm{CI}: 1.00-1.09$ and $\mathrm{OR}=0.89$, 95\%CI: $0.84-0.94$, respectively). Multivariate logistic regression analysis showed that female age was independently associated with the rate of ongoing pregnancy $(\mathrm{OR}=0.90,95 \% \mathrm{CI}: 0.855-0.953, P<0.01)$ whereas no 
Table 2 Clinical baseline

\begin{tabular}{|c|c|c|c|}
\hline Demographics & Patients with AMH > 10th centile $(n=847)$ & Patients with AMH $\leq 10$ th centile $(n=62)$ & \\
\hline Female age, yrs & $33.3 \pm 5.0$ & $33.8 \pm 5.0$ & 0.46 \\
\hline $\mathrm{BMl}, \mathrm{kg} / \mathrm{m} 2$ & $21.6 \pm 2.9$ & $21.6 \pm 2.8$ & 0.99 \\
\hline Duration of infertility, months & $39 \pm 32$ & $40 \pm 31$ & 0.82 \\
\hline Menstrual period, days & $30 \pm 4$ & $28 \pm 3$ & 0.003 \\
\hline Women with prior live birth, $\mathrm{n}(\%)$ & $202(23.8 \%)$ & $14(22.6 \%)$ & 0.46 \\
\hline Regular menstruation & $728(86 \%)$ & $56(90.3)$ & 0.34 \\
\hline Ovary surgery history, n (\%) & $68(8 \%)$ & $4(6.5 \%)$ & \\
\hline Causes for infertility, n (\%) & & & $<0.01$ \\
\hline Tubal factor & $359(42.4 \%)$ & $4(6.5 \%)$ & \\
\hline DOR & $80(9.4 \%)$ & $55(88.7 \%)$ & \\
\hline PCOS & $106(12.5 \%)$ & 0 & \\
\hline Endometriosis & $61(7.2 \%)$ & $1(1.6 \%)$ & \\
\hline Adenomyosis & $12(1.4 \%)$ & 0 & \\
\hline Male factor & $173(20.4 \%)$ & $1(1.6 \%)$ & \\
\hline Combined & 19 (2.2\%) & $1(1.6 \%)$ & \\
\hline Unexplained & 37 (4.4\%) & 0 & \\
\hline $\mathrm{AMH}, \mathrm{ng} / \mathrm{ml}$ & $3.8 \pm 3.2$ & $0.4 \pm 0.3$ & $<0.01$ \\
\hline FSH, IU/L & $7.8 \pm 3.4$ & $14.7 \pm 7.9$ & $<0.01$ \\
\hline AFC & $12 \pm 7$ & $5 \pm 2$ & $<0.01$ \\
\hline
\end{tabular}

BMI Body mass index, DOR Decreased ovarian reserve, PCOS Polycystic ovary syndrome, AMH Anti-Mullerian hormone, FSH Follicle stimulation hormone, AFC Antral follicle count

statistical significance was reached in the association of ongoing pregnancy with $\mathrm{AMH}$ concentration and oocyte number. We further evaluated the pregnancy outcomes following the entire cohort of 1008 fresh or frozen embryo transfer cycles according AMH level and age (Table 6). The mean female age in these 4 subgroups divided by age and AMH level in Table 6 were respectively $30.3 \pm 2.6,28.8 \pm 2.7,38.7 \pm 3.0$ and $38.5 \pm 3.9$ years. In patients younger than 35 years, significant differences between AMH subgroups were detected in clinical pregnancy per transfer $(p=0.003)$, miscarriage per clinical pregnancy $(p=0.015)$ and ongoing pregnancy per transfer $(p=0.001)$. Again, these differences between AMH subgroups were not reached in patients older than 35 years (Table 6).

Given that an AMH cut-off value of $1.0 \mathrm{ng} / \mathrm{ml}$ was used to define ovarian reserve in previous studies [16], Table 7 was added to correlate the fertility outcome with low AMH value (lower than $1.0 \mathrm{ng} / \mathrm{ml}$ ). Statistical significance in clinical pregnancy per transfer and ongoing pregnancy per transfer $(p=0.001)$ was found between subgroup divided by absolute value of AMH according to patient age. In the subgroup of age after 35, women with $\mathrm{AMH}$ lower than $10^{\text {th }}$ centile had a lower clinical pregnancy per transfer and ongoing pregnancy per transfer compared to women with AMH lower than 1

Table 3 Outcome of ovary stimulation and embryo culture

\begin{tabular}{|c|c|c|c|}
\hline & $\begin{array}{l}\text { Retrieval cycles with AMH } \\
>\text { 10th centile }(n=1134)\end{array}$ & $\begin{array}{l}\text { Retrieval cycles with AMH } \\
\leq 10 \text { th centile }(n=147)\end{array}$ & $P$ value \\
\hline Days of ovarian stimulation per cycle & $10.1 \pm 3.5$ & $6.6 \pm 5.2$ & $<0.01$ \\
\hline Total gonadotropin dose (IU) per cycle & $2690 \pm 1368$ & $1802 \pm 1583$ & $<0.01$ \\
\hline Estradiol level on trigger day (pg/ml) & $2672 \pm 1579$ & $874 \pm 827$ & $<0.01$ \\
\hline Endometrial thickness on trigger day $(\mathrm{mm})$ & $9.4 \pm 7.0$ & $7.5 \pm 2.8$ & $<0.01$ \\
\hline Total number of oocytes per cycle & $9.6 \pm 6.9$ & $2.2 \pm 3.4$ & $<0.01$ \\
\hline Number of MII oocytes per cycle & $8.5 \pm 6.4$ & $1.9 \pm 2.9$ & $<0.01$ \\
\hline Total number of embryos available for transfer per cycle & $3.4 \pm 2.7$ & $0.8 \pm 1.1$ & $<0.01$ \\
\hline Number of D5 or D6 blastocysts available for transfer per cycle & $1.1 \pm 1.7$ & $0.1 \pm 0.3$ & $<0.01$ \\
\hline
\end{tabular}


Table 4 Outcome of ovary stimulation and embryo culture by AMH percentile according to age

\begin{tabular}{|c|c|c|c|}
\hline & \multicolumn{2}{|l|}{ Age of patients $<35$} & \multirow[t]{2}{*}{$P$ value } \\
\hline & $\begin{array}{l}\text { Retrieval cycles with AMH > 10th centile } \\
(n=614)\end{array}$ & $\begin{array}{l}\text { Retrieval cycles with AMH } \\
\leq 10 \text { th centile }(n=84)\end{array}$ & \\
\hline Days of ovarian stimulation & $11 \pm 2.5$ & $7.2 \pm 5.1$ & $<0.01$ \\
\hline Total gonadotropin dose (IU) & $2850 \pm 1302$ & $1853 \pm 1525$ & $<0.01$ \\
\hline Estradiol level on trigger day $(\mathrm{pg} / \mathrm{ml})$ & $3187 \pm 1454$ & $980 \pm 882$ & $<0.01$ \\
\hline Endometrial thickness on trigger day (mm) & $10.2 \pm 2.7$ & $7.6 \pm 2.9$ & $<0.01$ \\
\hline Total number of oocytes retrieved & $12.3 \pm 6.5$ & $2.7 \pm 4.0$ & $<0.01$ \\
\hline Number of MIl oocytes retrieved & $10.9 \pm 6.2$ & $2.4 \pm 3.3$ & $<0.01$ \\
\hline Total number of embryo available for transfer & $4.3 \pm 2.8$ & $1.0 \pm 1.2$ & $<0.01$ \\
\hline \multirow[t]{3}{*}{ Number of D5 or D6 blastocyst available for transfer } & $1.5 \pm 1.9$ & $0.1 \pm 0.4$ & $<0.01$ \\
\hline & \multicolumn{3}{|l|}{ Age of patients $\geq 35$} \\
\hline & $\begin{array}{l}\text { Retrieval cycles with AMH > 10th centile } \\
(n=520)\end{array}$ & $\begin{array}{l}\text { Retrieval cycles with AMH } \\
\leq 10 \text { th centile }(n=63)\end{array}$ & \\
\hline Days of ovarian stimulation & $9.1 \pm 4.2$ & $5.5 \pm 5.2$ & $<0.01$ \\
\hline Total gonadotropin dose (IU) & $2500 \pm 1420$ & $1728 \pm 1677$ & $<0.01$ \\
\hline Estradiol level on trigger day $(\mathrm{pg} / \mathrm{ml})$ & $2061 \pm 1503$ & $740 \pm 735$ & $<0.01$ \\
\hline Endometrial thickness on trigger day (mm) & $8.5 \pm 3.1$ & $7.3 \pm 2.7$ & $<0.01$ \\
\hline Total number of oocytes retrieved & $6.4 \pm 5.9$ & $1.5 \pm 2.1$ & $<0.01$ \\
\hline Number of mature oocytes retrieved & $5.7 \pm 5.4$ & $1.3 \pm 2.0$ & $<0.01$ \\
\hline Total number of embryo available for transfer & $2.4 \pm 2.2$ & $0.6 \pm 0.8$ & $<0.01$ \\
\hline Number of D5 or D6 blastocyst available for transfer & $0.6 \pm 1.2$ & $0.1 \pm 0.3$ & $<0.01$ \\
\hline
\end{tabular}

Table 5 Comparison of embryo transfer by AMH percentile according to patient age

\begin{tabular}{|c|c|c|c|}
\hline & \multicolumn{2}{|l|}{ Age of patients $<35$} & \multirow[t]{2}{*}{$P$ value } \\
\hline & $\begin{array}{l}\text { Embryo transfer with AMH }>10 \text { th centile } \\
(n=582)\end{array}$ & $\begin{array}{l}\text { Embryo transfer with } A M H \leq 10 \text { th centile } \\
(n=32)\end{array}$ & \\
\hline Fresh embryo transfer & $191(32.8 \%)$ & $10(31.2 \%)$ & 0.85 \\
\hline Mean number of embryos transferred & $1.9 \pm 0.4$ & $1.8 \pm 0.4$ & 0.17 \\
\hline One embryo transferred & $94(16.2 \%)$ & $8(25 \%)$ & 0.19 \\
\hline Two embryos transferred & $488(83.9 \%)$ & $24(75 \%)$ & - \\
\hline D3 embryo transfer & $458(78.7 \%)$ & $31(96.9 \%)$ & 0.003 \\
\hline Blastocyst transfer & $124(21.3 \%)$ & $1(3.1 \%)$ & 0.11 \\
\hline D5 blastocyst & $93(16 \%)$ & $1(3.1 \%)$ & _- \\
\hline \multirow[t]{3}{*}{ D6 blastocyst } & $31(5.3 \%)$ & 0 & - \\
\hline & \multicolumn{3}{|l|}{ Age of patients $\geq 35$} \\
\hline & $\begin{array}{l}\text { Embryo transfer with AMH }>10 \text { th centile } \\
(n=384)\end{array}$ & $\begin{array}{l}\text { Embryo transfer with } A M H \leq 10 \text { th centile } \\
(n=10)\end{array}$ & \\
\hline Fresh embryo transfer & $123(32.2 \%)$ & $3(30 \%)$ & 1.00 \\
\hline Mean number of embryos transferred & $1.8 \pm 0.4$ & $1.5 \pm 0.5$ & 0.02 \\
\hline One embryo transferred & $74(19.7 \%)$ & $5(50 \%)$ & 0.019 \\
\hline Two embryos transferred & $320(81.3 \%)$ & $5(50 \%)$ & \\
\hline D3 embryo transfer & $304(81.8 \%)$ & $9(90 \%)$ & 0.47 \\
\hline Blastocyst transfer & $72(18.2 \%)$ & $1(10 \%)$ & - \\
\hline D5 blastocyst & 43 (11.4\%) & 0 & - \\
\hline D6 blastocyst & $29(7.7 \%)$ & $1(10 \%)$ & \\
\hline
\end{tabular}


Table 6 Pregnancy outcome after embryo transfer by AMH percentile according to patient age

\begin{tabular}{|c|c|c|c|}
\hline & \multicolumn{2}{|l|}{ Age of patients $<35$} & \multirow[t]{2}{*}{$P$ value } \\
\hline & $\begin{array}{l}\text { Embryo transfer with AMH } \\
>\text { 10th centile }(n=582)\end{array}$ & $\begin{array}{l}\text { Embryo transfer with AMH } \\
\leq 10 \text { th centile }(n=32)\end{array}$ & \\
\hline Positive hCG per transfer & $62.5 \%(364 / 582)$ & $37.5 \%(12 / 32)$ & 0.005 \\
\hline Positive hCG per D3 embryo transfer & $62.7 \%(287 / 458)$ & $35.5 \%(11 / 31)$ & 0.002 \\
\hline Positive hCG per blastocyst transfer & $62.1 \%(77 / 124)$ & $100 \%(1 / 1)$ & 1.00 \\
\hline Biochemical pregnancy per transfer & $4.6 \%(27 / 582)$ & $6.3 \%(2 / 32)$ & 0.62 \\
\hline Ectopic pregnancy per transfer & $0.9 \%(5 / 582)$ & 0 & 1.0 \\
\hline Clinical pregnancy per transfer & $57 \%(332 / 582)$ & $31.3 \%(10 / 32)$ & 0.003 \\
\hline Miscarriage per clinical pregnancy & $9 \%(30 / 332)$ & $30 \%(3 / 10)$ & 0.015 \\
\hline Ongoing pregnancy per transfer & $51.9 \%(302 / 582)$ & $21.9 \%(7 / 32)$ & 0.001 \\
\hline Ongoing pregnancy per D3 embryo transfer & $51.3 \%(235 / 458)$ & $19.4 \%(6 / 31)$ & 0.001 \\
\hline \multirow[t]{3}{*}{ Ongoing pregnancy per blastocyst transfer } & $54 \%(67 / 124)$ & $100 \%(1 / 1)$ & 1.0 \\
\hline & \multicolumn{3}{|l|}{ Age of patients $\geq 35$} \\
\hline & $\begin{array}{l}\text { Embryo transfer with AMH } \\
>10 \text { th centile }(n=384)\end{array}$ & $\begin{array}{l}\text { Embryo transfer with AMH } \\
\leq 10 \text { th centile }(n=10)\end{array}$ & \\
\hline Positive hCG per transfer & $46.1 \%(177 / 384)$ & $10 \%(1 / 10)$ & 0.026 \\
\hline Positive hCG per D3 embryo transfer & $43.6 \%(136 / 312)$ & $11.1 \%(1 / 9)$ & 0.005 \\
\hline Positive hCG per blastocyst transfer & $56.9 \%(41 / 72)$ & $0(0 / 1)$ & 0.43 \\
\hline Biochemical pregnancy per transfer & $4.4 \%(17 / 384)$ & 0 & - \\
\hline Ectopic pregnancy per transfer & 0 & 0 & - \\
\hline Clinical pregnancy per transfer & $41.7 \%(160 / 384)$ & $10 \%(1 / 10)$ & 0.049 \\
\hline Miscarriage per clinical pregnancy & $18.1 \%(29 / 160)$ & 0 & 1.00 \\
\hline Ongoing pregnancy per transfer & $34.1 \%(131 / 384)$ & $10 \%(1 / 10)$ & 0.175 \\
\hline Ongoing pregnancy per D3 embryo transfer & $31.1 \%(97 / 312)$ & $11.1 \%(1 / 9)$ & 0.285 \\
\hline Ongoing pregnancy per blastocyst transfer & $47.2 \%(34 / 72)$ & $0(0 / 1)$ & 1.00 \\
\hline
\end{tabular}

ng/ml ( $10 \%$ vs $22.1,10 \%$ vs $16.2 \%$, respectively), though no statistical significance was found.

\section{Discussion}

This study established an age-specific definition of low $\mathrm{AMH}$ concentration and further evaluated its impact on outcomes of assisted conceptions. The age-related $10^{\text {th }}$ centile of AMH concentrations was used as the cut-off value for low AMH level. The equation was as follows: $10^{\text {th }}$ centile $=(-0.107 \times$ age $)+3.39$. Based on this cut-off value, this study found that the pregnancy rate was significantly lower in women with low AMH concentration, especially when evaluated according to age.

$\mathrm{AMH}$ as a marker of ovarian reserve is well recognized and widely tested in clinical practice [2]. In accordance with previous studies, the present study showed the measurement of AMH was steadily decreased with advancing age $[13,14]$. In addition, the $\mathrm{AMH}$ concentrations were well correlated with the number of oocytes retrieved during COS procedures [3]. In a study by Hamdine and colleagues, the authors further found that
$\mathrm{AMH}$ had a higher accuracy for predicting ovarian response than female age and BMI [22].

However, the clinical utility of $\mathrm{AMH}$ for the prediction of pregnancy outcome remains controversial. In a previous study, Zhang et al. reported that the cumulative live birth in women with young age (<35 year) and low AMH level (defined as 0-25th percentage) and those with advanced age ( $\geq 35$ year) and low AMH level was respective 56.35\%(1025/1819) and 20.11\%(108/537) after the transfer of all embryos obtained in the first oocyte retrieval. In women with young age $(<35$ year) and low $\mathrm{AMH}$ level, a plateau of cumulative live birth was reached after three embryos transfer attempts [23]. The present study found that the ongoing pregnancy rate was about $20 \%$ in women with young age $(<35$ year) and low AMH level (defined as the 10th centile). Therefore, our study also provided evidence for young women with low AMH level to undergo more attempts of IVF treatments. This study presents that low AMH levels are negatively associated with implantation rate, clinical pregnancy and ongoing pregnancy rate in women younger than 35 years. Several studies also reported that 
Table 7 Pregnancy outcome after embryo transfer by absolute value of AMH according to patient age

\begin{tabular}{|c|c|c|c|}
\hline & \multicolumn{2}{|l|}{ Age of patients $<35$} & \multirow[t]{2}{*}{$P$ value } \\
\hline & $\begin{array}{l}\text { Embryo transfer with AMH } \\
\geq 1.0 \mathrm{ng} / \mathrm{ml}(n=576)\end{array}$ & $\begin{array}{l}\text { Embryo transfer with AMH } \\
<1.0 \mathrm{ng} / \mathrm{ml}(n=38)\end{array}$ & \\
\hline Positive hCG per transfer & $62.5 \%(360 / 576)$ & $42.1 \%(16 / 38)$ & 0.012 \\
\hline Positive hCG per D3 embryo transfer & $62.5 \%(283 / 453)$ & $35.5 \%(15 / 36)$ & 0.014 \\
\hline Positive hCG per blastocyst transfer & $62.6 \%(77 / 123)$ & $50 \%(1 / 2)$ & 1.00 \\
\hline Biochemical pregnancy per transfer & $4.9 \%(28 / 576)$ & $2.6 \%(1 / 38)$ & 1.00 \\
\hline Ectopic pregnancy per transfer & $0.9 \%(5 / 576)$ & 0 & 1.00 \\
\hline Clinical pregnancy per transfer & $56.8 \%(327 / 576)$ & $39.5 \%(15 / 38)$ & 0.038 \\
\hline Miscarriage per clinical pregnancy & $9.2 \%(30 / 327)$ & $20 \%(3 / 15)$ & 0.167 \\
\hline Ongoing pregnancy per transfer & $51.6 \%(297 / 576)$ & $31.6 \%(12 / 38)$ & 0.017 \\
\hline Ongoing pregnancy per D3 embryo transfer & $50.8 \%(230 / 453)$ & $30.6 \%(11 / 36)$ & 0.02 \\
\hline \multirow[t]{3}{*}{ Ongoing pregnancy per blastocyst transfer } & $54.5 \%(67 / 123)$ & $50 \%(1 / 2)$ & 1.00 \\
\hline & \multicolumn{3}{|l|}{ Age of patients $\geq 35$} \\
\hline & $\begin{array}{l}\text { Embryo transfer with AMH } \\
\geq 1.0 \mathrm{ng} / \mathrm{ml}(n=326)\end{array}$ & $\begin{array}{l}\text { Embryo transfer with AMH } \\
<1.0 \mathrm{ng} / \mathrm{ml}(n=68)\end{array}$ & \\
\hline Positive hCG per transfer & $49.1 \%(160 / 326)$ & $26.5 \%(18 / 68)$ & 0.001 \\
\hline Positive hCG per D3 embryo transfer & $46.5 \%(119 / 256)$ & $27.7 \%(18 / 65)$ & 0.006 \\
\hline Positive hCG per blastocyst transfer & $58.6 \%(41 / 70)$ & $0(0 / 3)$ & 0.08 \\
\hline Biochemical pregnancy per transfer & $4.3 \%(14 / 326)$ & $4.4 \%(3 / 68)$ & 1.00 \\
\hline Clinical pregnancy per transfer & $44.8 \%(146 / 326)$ & $22.1 \%(15 / 68)$ & 0.001 \\
\hline Miscarriage per clinical pregnancy & $17.1 \%(25 / 146)$ & $26.7 \%(4 / 15)$ & 0.573 \\
\hline Ongoing pregnancy per transfer & $34.1 \%(121 / 326)$ & $16.2 \%(11 / 68)$ & 0.001 \\
\hline Ongoing pregnancy per D3 embryo transfer & $34.0 \%(87 / 256)$ & $16.9 \%(11 / 65)$ & 0.008 \\
\hline Ongoing pregnancy per blastocyst transfer & $48.6 \%(34 / 70)$ & $0(0 / 3)$ & 0.243 \\
\hline
\end{tabular}

AMH concentrations were associated with the implantation, clinical pregnancy and live birth after IVF treatment $[5,6]$. Two studies respectively analyzed 603 and 892 patients and found that AMH levels were strongly associated with live birth after IVF conceptions [7, 24]. Other investigators, however, reported no or weak association of AMH with live birth [8-12]. For example, two recent systematic reviews and a large retrospective analysis of 85,062 cycles depicted AMH as a poor independent predictor for pregnancy outcome in IVF conceptions. Another study also showed that AMH provided little additional value for predicting 1-year cumulative live birth rate in GnRH antagonist treatment cycles [25]. The discrepancy among these studies may be mainly due to the confounding impact of age. Given that AMH levels decreases steadily with age, the cut-off value for low AMH may thus be evaluated according to age. Nevertheless, most studies adopted a uniform cut-off value of low AMH level for all women. In addition, the option of cut-off value of low AMH level are slightly different in these studies ranging from 0.4 to $2.7 \mathrm{ng} / \mathrm{ml}$ [12].

The main strength of this study is the application of age-specific definition for low AMH level. The age- related cut-off value may be not as clinically pragmatic as the single threshold for all ages. However, it is helpful to minimize the mixed effect of age on the association between low AMH level and pregnancy outcome following IVR treatment. In addition, the third-generation automated AMH assay was employed for the measures in the present study [26]. Several studies show that the automated AMH assay is more sensitive than the Gen-II ELISA kit [27]. The automated AMH assay avoids getting lost in the AMH values, especially the extremely low values and enables establishing more accurate reference [28-30].

There are several limitations in this study. First, the measurement of AMH was introduced into our center from 2016. Therefore, the circulating AMH levels was not tested in all the women undergoing IVF treatment at the beginning. This may result in a bias of patient selection. Second, the small sample size of women with low AMH level and older than 35 years limits a firm conclusion on the association between low AMH level and pregnancy outcome in this population. A debate on offering IVF treatment for these patients continues. In addition, the optimal method to determine the clinically 
most useful low $\mathrm{AMH}$ is to use $\mathrm{AMH}$ value from each specific age as continuous variable and assess its correlation with outcome parameters. However, this methodology would require a dataset too large to be practical for a single center study. Therefore, we adopted a more pragmatic methodology in this study. In brief, the agespecific reference of AMH was built by polynomial leastsquares regression analysis. Given that around 10-30\% of patients presenting to doctors with infertility were diagnosed as decreased ovarian reserve based on an AMH level around $1.0 \mathrm{ng} / \mathrm{ml}$ or 10th centile [31-33], this study also chose the age-specific $10^{\text {th }}$ centile as the cut-off value of low AMH. However, the sample size of patients with extremely low AMH level ( $5^{\text {th }}$ centile) were quite small in the present study, which not only prevents meaningful analysis, but also obscure the significant association between low AMH and pregnancy outcome. Large studies with more patients with low AMH level are required to confirm our findings. The dichotomization of the outcomes (age and AMH), though clinically useful, may lead to a considerable loss of statistical power of the analysis, missing information and potentially biased effect estimates on individual patient. In particular, dichotomization leads to a considerable loss of power and incomplete correction for confounding factors. Moreover, Extended blastocyst-stage embryo culture in women with advanced age is full of debate. Several studies demonstrated that blastocyst development rate and implantation rate after blastocyst transfer was negatively related to increasing female aging [33, 34]. In a Cochrane systematic review, the evidence of blastocyst culture in women with advanced age is quite limited [35, 36]. In our practice, women with advanced age are often afraid of the failure in blastocyst culture and losing the opportunity to transfer cleavage-stage embryos. As a result, the blastocyst culture is less performed in women with advanced age than young women. Noticeably, it is well recognized that serum $\mathrm{AMH}$ is an excellent indicator of the number of oocytes and embryos per ovarian stimulation cycle. The higher serum AMH is, the more oocytes and embryos yields per ovarian stimulation cycle. In this sense, AMH may foresee cumulative pregnancy outcome during IVF treatment. Large and perspective studies are required to show the association between centiles-different AMH and cumulative live birth in patients at same ages.

\section{Conclusion}

Our findings suggest that low AMH concentrations are associated with poor ovarian stimulation and pregnancy rate in women younger than 35 years. Large studies are required to investigate the predictive value of agespecific low AMH levels for pregnancy outcomes in women older than 35 years.

\section{Abbreviations}

AFC: Antral follicle count; AMH: Anti-Mullerian hormone; $\beta$-hCG: $\beta$ human chorionic gonadotrophin; BMI: Body mass index; COS: Controlled ovarian stimulation; DOR: Decreased ovarian reserve; D3: Day 3; D5: Day 5; D6: Day 6; FSH: Follicle stimulation hormone; IU: International unit; IVF: In vitro fertilization; PCOS: Polycystic ovary syndrome; TGF- $\beta$ : Transforming growth factor- $\beta$

\section{Acknowledgements}

We are greatly indebted to Dr. John Yeh (Massachusetts General Hospital, Harvard Medical School) and Dr. Haibin Wang (Xiamen University) for their critical review on this manuscript.

\section{Authors' contributions}

DZ conceptualized and designed the study, and wrote the first draft of the manuscripts. JF and $\mathrm{HC}$ carried out the clinical data collection and data analysis. $\mathrm{PW}, \mathrm{XJ}, J \mathrm{Y}$ and $\mathrm{XL}$ reviewed and revised the manuscripts. All authors read and approved the final manuscript.

\section{Authors' information}

Not applicable.

\section{Funding}

This project was funded by the National Natural Science Foundation of China (Grant Number: 81801465), Shenzhen Key Medical Discipline Construction Fund (Grant Number: SZXK031), Science, Technology and Innovation Commission of Shenzhen Municipality (Grant Number: JCYJ20200109150410232 and

JCYJ20190809165601673) and the Shenzhen Maternity \& Child Healthcare Hospital Science Foundation (Grant Number: FYA2018002). The funding bodies played no role in the design of the study and collection, analysis, and interpretation of data and in writing the manuscript.

\section{Availability of data and materials}

The raw dataset analyzed in the current study are available from the corresponding author on reasonable request.

\section{Declarations}

Ethics approval and consent to participate

This study was approved by the Medical Ethics Committee of Shenzhen Maternity and Child Healthcare Hospital (SFYLS2019048). Given the retrospective nature of this study, the informed consent waived by the Medical Ethics Committee of Shenzhen Maternity and Child Healthcare Hospital.

Consent for publication

Not applicable.

\section{Competing interests}

We have no conflict of interest to declare.

Received: 8 February 2020 Accepted: 18 February 2021

Published online: 05 March 2021

\section{References}

1. Broer SL, Broekmans FJ, Laven JS, Fauser BC. Anti-Mullerian hormone: ovarian reserve testing and its potential clinical implications. Hum Reprod Update. 2014;20(5):688-701.

2. Dewailly D, Andersen CY, Balen A, Broekmans F, Dilaver N, Fanchin R, Griesinger G, Kelsey TW, La Marca A, Lambalk C, et al. The physiology and clinical utility of anti-Mullerian hormone in women. Hum Reprod Update. 2014;20(3):370-85

3. Gnoth C, Roos J, Broomhead D, Schiffner J, Godehardt E, Freundl G, Johnson S. Antimullerian hormone levels and numbers and sizes of antral follicles in regularly menstruating women of reproductive age referenced to true ovulation day. Fertil Steril. 2015;104(6):1535-1543.e1531-1534.

4. Broer SL, van Disseldorp J, Broeze KA, Dolleman M, Opmeer BC, Bossuyt P, Eijkemans MJ, Mol BW, Broekmans FJ. Added value of ovarian reserve testing on patient characteristics in the prediction of ovarian response and 
ongoing pregnancy: an individual patient data approach. Hum Reprod Update. 2013;19(1):26-36.

5. Eldar-Geva T, Ben-Chetrit A, Spitz IM, Rabinowitz R, Markowitz E, Mimoni T, Gal M, Zylber-Haran E, Margalioth EJ. Dynamic assays of inhibin B, antiMullerian hormone and estradiol following FSH stimulation and ovarian ultrasonography as predictors of IVF outcome. Hum Reprod (Oxford, England). 2005;20(11):3178-83.

6. Nelson SM, Yates RW, Fleming R. Serum anti-Mullerian hormone and FSH: prediction of live birth and extremes of response in stimulated cycles-implications for individualization of therapy. Hum Reprod (Oxford, England). 2007;22(9):2414-21.

7. Brodin T, Hadziosmanovic N, Berglund L, Olovsson M, Holte J. Antimullerian hormone levels are strongly associated with live-birth rates after assisted reproduction. J Clin Endocrinol Metab. 2013;98(3):1107-14.

8. Tal R, Tal O, Seifer BJ, Seifer DB. Antimullerian hormone as predictor of implantation and clinical pregnancy after assisted conception: a systematic review and meta-analysis. Fertil Steril. 2015;103(1):119-130.e113.

9. Alson SSE, Bungum L, Giwercman A, Henic E. Anti-mullerian hormone levels are associated with live birth rates in ART, but the predictive ability of anti-mullerian hormone is modest. Eur J Obstet Gynecol Reprod Biol. 2018; 225:199-204.

10. Smeenk JM, Sweep FC, Zielhuis GA, Kremer JA, Thomas CM, Braat DD. Antimullerian hormone predicts ovarian responsiveness, but not embryo quality or pregnancy, after in vitro fertilization or intracyoplasmic sperm injection. Fertil Steril. 2007;87(1):223-6.

11. Tal R, Seifer DB, Wantman E, Baker V, Tal O. Antimullerian hormone as a predictor of live birth following assisted reproduction: an analysis of 85,062 fresh and thawed cycles from the Society for Assisted Reproductive Technology Clinic Outcome Reporting System database for 2012-2013. Fertil Steril. 2018;109(2):258-65.

12. Iliodromiti S, Kelsey TW, Wu O, Anderson RA, Nelson SM. The predictive accuracy of anti-Mullerian hormone for live birth after assisted conception: a systematic review and meta-analysis of the literature. Hum Reprod Update. 2014;20(4):560-70.

13. Aksglaede $L$, Sorensen $K$, Boas M, Mouritsen A, Hagen CP, Jensen RB, Petersen $\mathrm{JH}$, Linneberg A, Andersson AM, Main KM, et al. Changes in antiMullerian hormone (AMH) throughout the life span: a population-based study of 1027 healthy males from birth (cord blood) to the age of 69 years. J Clin Endocrinol Metab. 2010;95(12):5357-64.

14. Lie Fong S, Visser JA, Welt CK, de Rijke YB, Eijkemans MJ, Broekmans FJ, Roes EM, Peters WH, Hokken-Koelega AC, Fauser BC, et al. Serum antimullerian hormone levels in healthy females: a nomogram ranging from infancy to adulthood. J Clin Endocrinol Metab. 2012;97(12):4650-5.

15. Franasiak JM, Forman EJ, Hong KH, Werner MD, Upham KM, Treff NR, Scott RT Jr. The nature of aneuploidy with increasing age of the female partner: a review of 15,169 consecutive trophectoderm biopsies evaluated with comprehensive chromosomal screening. Fertil Steril. 2014;101(3):656-663. e651.

16. Cohen J, Chabbert-Buffet N, Darai E. Diminished ovarian reserve, premature ovarian failure, poor ovarian responder--a plea for universal definitions. J Assist Reprod Genet. 2015;32(12):1709-12.

17. Chen ZJ, Shi Y, Sun Y, Zhang B, Liang X, Cao Y, Yang J, Liu J, Wei D, Weng $\mathrm{N}$, et al. Fresh versus frozen embryos for infertility in the polycystic ovary syndrome. N Engl J Med. 2016;375(6):523-33.

18. Jing J, Xia F, Ding Z, Chen L, Shao Y, Ge YF, Pan P, Tian T, Lan XP, Yao B. A single-center performance evaluation of the fully automated iFlash antiMullerian hormone immunoassay. Clin Chem Lab Med. 2018;57(2):e19-22.

19. Practice Committee of the American Society for Reproductive Medicine and the Practice Committee of the Society for Assisted Reproductive Technology. Criteria for number of embryos to transfer: a committee opinion. Fertil Steril. 2013;99(1):44-6.

20. Zhao DP, Li XM. Meeting Abstracts from the 2019 IFFS Shanghai World Congress. 2019;4(1):e30 PS203.

21. Luke B, Brown MB, Wantman E, Lederman A, Gibbons W, Schattman GL, Lobo RA, Leach RE, Stern JE. Cumulative birth rates with linked assisted reproductive technology cycles. N Engl J Med. 2012;366(26):2483-91.

22. Hamdine O, Eijkemans MJ, Lentjes EW, Torrance HL, Macklon NS, Fauser BC, Broekmans FJ. Ovarian response prediction in $\mathrm{GnRH}$ antagonist treatment for IVF using anti-Müllerian hormone. Hum Reprod (Oxford, England). 2015; $30(1): 170-8$
23. Zhang B, Meng Y, Jiang X, Liu C, Zhang H, Cui L, Chen ZJ. IVF outcomes of women with discrepancies between age and serum anti-Müllerian hormone levels. Reprod Biol Endocrinol. 2019;17(1):58.

24. Lukaszuk K, Liss J, Kunicki M, Jakiel G, Wasniewski T, Woclawek-Potocka I, Pastuszek E. Anti-Mullerian hormone (AMH) is a strong predictor of live birth in women undergoing assisted reproductive technology. Reprod Biol. 2014; 14(3):176-81.

25. Hamdine O, Eijkemans MJC, Lentjes EGW, Torrance HL, Macklon NS, Fauser $\mathrm{B}$, Broekmans FJ. Antimüllerian hormone: prediction of cumulative live birth in gonadotropin-releasing hormone antagonist treatment for in vitro fertilization. Fertil Steril. 2015;104(4):891-898.e892.

26. Segawa T, Omi K, Watanabe Y, Sone Y, Handa M, Kuroda M, Miyauchi O, Osada H, Teramoto S. Age-specific values of access anti-Mullerian hormone immunoassay carried out on Japanese patients with infertility: a retrospective large-scale study. BMC Womens Health. 2019;19(1):57.

27. Su HI, Sammel MD, Homer MV, Bui K, Haunschild C, Stanczyk FZ. Comparability of antimüllerian hormone levels among commercially available immunoassays. Fertil Steril. 2014;101(6):1766-1772.e1761.

28. Nelson SM, La Marca A. The journey from the old to the new AMH assay: how to avoid getting lost in the values. Reprod BioMed Online. 2011;23(4): 411-20.

29. Jacobs MH, Reuter LM, Baker VL, Craig LB, Sakkas D, Surrey E, Doody KJ, Jungheim ES, Bayrak AB, Hund $M$, et al. A multicentre evaluation of the Elecsys $\left({ }^{\oplus}\right)$ anti-Müllerian hormone immunoassay for prediction of antral follicle count. Reprod BioMed Online. 2019;38(5):845-52.

30. Yue CY, Wu Y, Duan $\mathrm{CH}$, Wei J, Zhang D, Luo XH, Zhang QL, Ying CM. Performance evaluation of a fully automated anti-Müllerian hormone immunoassay and multicentre study on the establishment of reference range in adult women. Ann Clin Biochem. 2020;57(2):170-7.

31. Ebner T, Sommergruber M, Moser M, Shebl O, Schreier-Lechner E, Tews G. Basal level of anti-Müllerian hormone is associated with oocyte quality in stimulated cycles. Hum Reprod (Oxford England). 2006;21(8):2022-6.

32. La Marca A, Sighinolfi G, Radi D, Argento C, Baraldi E, Artenisio AC, Stabile G, Volpe A. Anti-Mullerian hormone (AMH) as a predictive marker in assisted reproductive technology (ART). Hum Reprod Update. 2010;16(2):113-30.

33. Shand AW, Whitton K, Pasfield A, Nassar N, MCShane M, Han X, Henry A. Evaluation of anti-Mullerian hormone in the first trimester as a predictor for hypertensive disorders of pregnancy and other adverse pregnancy outcomes. Aust N Z J Obstet Gynaecol. 2014;54(3):244-9.

34. Capalbo A, Rienzi L, Cimadomo D, Maggiulli R, Elliott T, Wright G, Nagy ZP, Ubaldi FM. Correlation between standard blastocyst morphology, euploidy and implantation: an observational study in two centers involving 956 screened blastocysts. Hum Reprod. 2014;29(6):1173-81.

35. Pantos K, Athanasiou V, Stefanidis K, Stavrou D, Vaxevanoglou T, Chronopoulou M. Influence of advanced age on the blastocyst development rate and pregnancy rate in assisted reproductive technology. Fertil Steril. 1999;71(6):1144-6.

36. Glujovsky D, Farquhar C, Quinteiro Retamar AM, Alvarez Sedo CR, Blake D. Cleavage stage versus blastocyst stage embryo transfer in assisted reproductive technology. Cochrane Database Syst Rev. 2016;(6):Cd002118. https://doi.org/10.1002/14651858.CD002118.pub5.

\section{Publisher's Note}

Springer Nature remains neutral with regard to jurisdictional claims in published maps and institutional affiliations.

Ready to submit your research? Choose BMC and benefit from:

- fast, convenient online submission

- thorough peer review by experienced researchers in your field

- rapid publication on acceptance

- support for research data, including large and complex data types

- gold Open Access which fosters wider collaboration and increased citations

- maximum visibility for your research: over $100 \mathrm{M}$ website views per year

At BMC, research is always in progress.

Learn more biomedcentral.com/submission 